\title{
İş Güvenliğinde Bulanık Promethee Yöntemiyle Hata Türleri ve Etkilerinin Analizi: Bir İnşaat Firmasında Uygulama
}

\author{
Burak EFE $^{1}$, Mehmet Akif YERLIKKAYA ${ }^{1 *}$, Ömer Faruk EFE ${ }^{2}$ \\ ${ }^{1}$ Gazi Üniversitesi, Mühendislik Fakültesi, Endüstri Mühendisliği Bölümü, 06570, Ankara \\ ${ }^{2}$ Gümüşhane Üniversitesi, Sağllk Yüksekokulu, İs Sağlı̆̆l ve Güvenliği Bölümü, 29000, Gümüşhane
}

Geliș tarihi/Received 25.04.2016

Düzeltilerek geliș tarihi/Received in revised form 01.07.2016

Kabul tarihi/Accepted 25.07.2016

$\ddot{O}_{z}$

Hata türleri ve etkileri analizi (HTEA) imalat ve hizmet sistemlerindeki potansiyel hatalar elimine etmek, tanımlamak için yaygın olarak kullanılan bir risk değerlendirme yöntemidir. Geleneksel HTEA'da olasılık (O), şiddet (S) ve saptanabilirlik (D) gibi risk faktörleri skorlarının çarpımılla elde edilen risk öncelik puanı kullanılarak hata türlerinin risk öncelikleri belirlenir. Ancak, kesin değerlerin kullanıldı̆̆ risk öncelik puanı yönteminde bazı eksiklikler olduğu için eleş̧tirilmiştir. Bu çalışmada; $O, S$ ve D risk faktörlerine ait ağırlıkları değerlendirmek için üçgensel bulanık sayılarla ifade edilen dilsel değişkenler kullanılmuştır. En ciddi hata türlerinin seçiminde, önceden teşhis edilen hata türlerinin risk önceliklerini belirlemek için bulanık B-PROMETHEE yöntemi önerilmiştir. Önerilen yöntemin bulanık ortamda uygulamasını göstermek için örnek bir çalışma sunulmuştur.

Anahtar Kelimeler: Bulanık PROMETHEE, Hata türleri ve etkileri analizi, Risk değerlendirme

\section{Failure Mode and Effects Analysis with Fuzzy Promethee Method in Occupational Accidents: An Application in a Construction Firm}

\begin{abstract}
Failure mode and effects analysis (FMEA) is a extensively employed risk evaluation tool for identifying and eliminating potential failures in manufacturing and service systems. In conventional $F M E A$, the risk priorities of failure modes are defined with so-called risk priority numbers (RPNs), which can be achieved by multiplying the scores of risk factors like occurrence $(O)$, severity $(S)$, and detection (D). However, the crisp RPN method has been criticized to have several shortcomings. In this study, linguistic variables, expressed triangular fuzzy numbers, are used to assess $\mathrm{O}, \mathrm{S}$ and D risk factors related to weights. For selecting the most serious failure modes, Fuzzy PROMETHEE method is proposed to determine risk priorities of the failure modes that have been identified. A case study is presented to demonstrate the efficiency of the suggested method under fuzzy environment.
\end{abstract}

Keywords: Fuzzy PROMETHEE, Failure mode and effects analysis, Risk evaluation

\footnotetext{
*Mehmet Akif YERLIKAYA, akifyerlikaya@gazi.edu.tr, Tel: (0 312) 5823846
} 


\section{Giriş}

Risk, üretim faaliyetinin doğal bir sonucu olarak meydana gelebilmektedir. Bütün risklerin yok edilebileceğini söylemek mümkün değildir fakat riskleri kabul edilebilir seviyeye getirmek mümkündür. Risk değerlendirme, beklenmeyen hataları engellemek için uygun teknikler kullanılarak uygulanır (Vahdani vd., 2015). Bu durumda, her bir hata türü ve etkisini risk değerlerine göre önceliklendirmek ve değerlendirmek gerekmektedir. Yüksek riskli (veya en tehlikeli) hata türü en öncelikli olarak düzeltilmelidir. Geleneksel HTEA risk öncelik sayısı (RÖS) metodunu kullanarak hata türlerinin risk önceliklerini belirlemektedir.

Geleneksel HTEA gerçek hayat problemlerinde uygulandığında kesin RÖS metodu bazı önemli eksiklikler göstermektedir. $\mathrm{Bu}$ dezavantajları ortadan kaldırmak için literatürde yapılmış olan çalışmaların bir kısmı aşağıda sunulmuştur.

HTEA metodunun etkinliğini arttırmak için TOPSIS (technique for ordering preference by similarity to ideal solution) (Song vd., 2013), VIKOR (Liu vd., 2012), analitik hiyerarşi prosesi (AHP) (Sachdeva vd., 2008), gri teori (Tan ve Du, 2013; Zhou ve Thai, 2016), veri zarflama analizi (VZA) (Chang ve Sun, 2009), sezgisel bulanık hibrid TOPSIS (Liu vd., 2015), bulanık önceliklendirme metodu (Özfirat, 2014), kaba TOPSIS (Song vd., 2014), DEMATEL (decision making trial and evaluation laboratory) (Chang vd., 2013b; Seyed-Hosseini vd., 2006), uzman sistem (Sankar ve Prabhu, 2001; Sharma vd., 2005), hibrid yaklaşımlar (Kutlu ve Ekmekcioğlu, 2012; Chang vd., 2013a, Vahdani vd., 2015; Liu vd.,2014) vb. yöntemler önerilmiştir. HTEA metodu tanker ekipman hata tahmini (Zhou ve Thai, 2016), çelik üretim süreci (Vahdani vd., 2015), gemi ekipman hataları (Tan ve Du, 2013), motor sistemleri (Xu vd., 2002), otomotiv sanayi (Kutlu ve Ekmekcioğlu, 2012), maden sektörü (Özfirat, 2014) ve anestezi süreci (Liu vd., 2012) gibi farklı birçok alanda uygulanmıştır. Kesin sayı metotlarıyla karşılaştırıldığında bulanık mantık yaklaşımı aşağıdaki avantajları sağlamaktadır (Sharma vd., 2005; Xu vd., 2002; Liu vd., 2012; Wang vd., 2009).

İlk olarak, kantitatif veri ve belirsiz olarak tanımlanan kalitatif bilgi kullanılabilir ve HTEA sirasında tutarlı durumda yönetilir. İkinci olarak, hata türleriyle ilgili risk dilsel değişkenler kullanılarak direkt olarak değerlendirilebilir. Son olarak, bulanık mantık belirsiz veriyi kullanmaya izin verir, böylece HTEA'daki birçok bulanık bilgi ifade edilebilir.

İnşaatlarda birçok potansiyel hata türü mevcuttur. Bu hata türleri gerçekleştiği zaman firmalara oldukça yüksek maliyet getirmektedir. $\mathrm{Bu}$ maliyetleri azaltmak amacıyla inşaat firmalarında güvenli bir iş ortamı oluşturmak gerekmektedir. HTEA metodu bir hata meydana gelmeden önce o hatayı tespit edebilen ve sonrasinda onu ortadan kaldırmak veya etkisini azaltmak için kullanılan bir analiz tekniğidir. Bu çalışmada risk değerlendirme için HTEA'nın bu özelliğinden yararlanılmıştır. Yukarıda ifade edildiği gibi geleneksel HTEA'da kullanılan RÖS metodunun eksikliklerini ortadan kaldırmak için birçok ölçütlü karar verme yaklaşımı olan PROMETHEE yöntemi bu çalışmada incelenmiştir.

$\mathrm{Bu}$ çalışmanın amacı, PROMETHEE (Preference Ranking Organization Method for Enrichment Evaluation) yöntemini bulanık ortamda genişleterek bir inşaat firmasında risk değerlendirmesi için bir karar destek sistemi kurmaktır. $\mathrm{O}, \mathrm{S}$ ve $\mathrm{D}$ risk faktörlerine ait önem derecelerini belirlemek için dilsel değişkenler kullanılmıştır. Geleneksel HTEA'daki kesin sayıların kullanıldığ 1-10 ölçeği yerine uzmanların görüşlerini daha kolay ifade edebileceği dilsel değişkenler kullanılmıştır. Hata türlerinin risk önceliklerini belirlemek için bulanık PROMETHEE (B-PROMETHEE) yöntemi önerilmiştir. Literatürde HTEA ile risk değerlendirmesi yaparken B-PROMETHEE yöntemini kullanan çalışmaya rastlanmamıştır. Önerilen yöntem, inşaat 
sektöründe gerçek hayat problemi üzerinde incelenmiştir.

$\mathrm{Bu}$ çalışmanın geri kalanı aşağıdaki gibidir. Geleneksel HTEA ve onun eksiklikleri Bölüm 2'de kısaca anlatılmıştır. Bölüm 3'te çalışmada kullanılan yöntem ve Bölüm 4'te uygulama ve elde edilen sonuçlar anlatılmıştır. Son bölümde ise sonuç verilmiştir.

\section{Hata Türleri ve Etkileri Analizi}

Hata türleri ve etkileri analizi (HTEA) ilk olarak 1960'larda havacılık endüstrisinde tasarım metodolojisi olarak geliştirilmiştir (Bowles ve Pelaez, 1995). HTEA, potansiyel tehlikeleri değerlendiren ve onları meydana gelmeden önleyen faydalı ve güçlü bir araçtır (Sankar ve Prabhu, 2001). HTEA imalat ve hizmet sistemlerindeki potansiyel hataları elimine etmek, tanımlamak için yaygın olarak kullanılan bir risk değerlendirme yöntemidir. Hata türü, tasarım amacını gerçekleştirirken parçada, alt sistemde, sistemde, süreçte vb. potansiyel olarak hatanın olabileceği durumlar olarak tanımlanmaktadır. Bir parçadaki hata türü başka bir parçada hata türünün sebebi olabilir. HTEA'nın diğer risk değerlendirme araçlarından farkı, hata olduktan sonra bir çözüm bulmak yerine sistemin önceden tespit etmesiyle bağlantıl1 olarak problemlerin yok edilmesidir. $\mathrm{Bu}$ durum karar vericilere mevcut programları düzeltmeye, hataların olabilirliğini azaltmak için önerilen faaliyetleri gerçekleştirmeye ve tehlikeli kazalardan sakınmaya yardım etmektedir. Günümüzde, HTEA havacılık, otomotiv, nükleer, elektronik, kimya ve tıp teknolojilerini kapsayan endüstrinin birçok alanında yaygın olarak kullanılmaktadır (Liu et al. 2012).

Hata türleri ve etkileri analizi; bir sistemin mevcut veya olası hata türlerini irdelemek için hataları ihtimallerine ve benzerliklerine göre ayıran ürün geliştirme ve operasyon sürecinin yönetim işleyişidir. Etkin bir hata türü analizi çalışması, benzer ürünlerin veya süreçlerin geçmiş deneyimlerinden yola çıkarak hata türlerinin tanımlanmasına olanak sağlar. Bununla birlikte, bu hataların sistemden minimum kaynak kullanımını ve çabayla bertaraf edilmesini sağlar. Bu bölümde, RÖS hesaplamasının parçaları olup ölçek tiplerine göre belirlenen olasılık, şiddet ve saptana bilirlik anlatılmıştır.

\subsection{Geleneksel HTEA}

Geleneksel HTEA bir hatanın meydana gelme olasılığının (O), şiddetinin (S) ve saptanabilirliğinin (D) çarpımı olan RÖS ile hata türlerinin risk önceliklerini belirler.

$R O ̈ S=O \times S \times D$

Bir potansiyel hata türünün RÖS'ünü elde etmek için üç risk faktörü Tablo 1-3'te (Ford Motor Company, 1988) görülen 10 puanlı ölçek kullanılarak değerlendirilir. Genellikle, daha yüksek RÖS'lü hata türlerinin daha önemli olduğu ve düzeltme için daha yüksek öncelik verileceği varsayılmaktadır.

\subsection{HTEA'nın Eksiklikleri}

HTEA sistem, tasarım, süreç veya hizmetteki gerçekleşebilecek hataları önceden önleyebilen en önemli erken önleyici faaliyetlerden biridir. Ancak, kesin RÖS'ler çeşitli sebeplerden dolayı eleştirilmektedir. Eleştirilerden bazıları aşağıda gösterilmektedir (Liu vd., 2012):

- O, S, D arasındaki önem dereceleri dikkate alınmaz. Üç faktörün eşit önem derecesine sahip olduğu kabul edilir. Bu gerçek hayat problemlerine HTEA'nın uygulamasında hatalı sonuçlar verebilir.

- O, S, D'nin farklı değerleri RÖS'ün aynı değerini tam olarak verebilir fakat onların gizli riskleri toplam olarak farklı olabilir. Örneğin 2 farklı durum için O, S, D sirasiyla 2, 3, 2 ve 4, 1, 3 ise RÖS değeri aynı ve 12 'dir. Bu durum kaynak ve zaman israfına veya daha yüksek riskli hata türünün belirlenememesine sebep olabilir.

- Üç faktörü kesin olarak değerlendirmek çok zordur. HTEA'da birçok bilgi genellikle belirsiz ve dilsel olarak önemli, çok yükssek vb. ifadelerle açıklanır. 
Tablo 1. Gerçekleşme olasılığının geleneksel HTEA ölçeği

\begin{tabular}{|l|l|l|}
\hline Sıra & Hatanın gerçekleşme olasılı̆̆ $\mathbf{~ ( O )}$ & Muhtemel hata oranı \\
\hline 10 & Aşırı yüksek, hatanın olması kaçınılmaz & 2 'de $\geq 1$ \\
\hline 9 & Çok yüksek & 3'de 1 \\
\hline 8 & Tekrarlı hatalar & $8^{\prime}$ de 1 \\
\hline 7 & Yüksek & 20 'de 1 \\
\hline 6 & Biraz yüksek & 80 'de 1 \\
\hline 5 & Orta & 400 'de 1 \\
\hline 4 & Biraz düşük & 2000 'de 1 \\
\hline 3 & Düşük & $15000^{\prime}$ de 1 \\
\hline 2 & Nadir & 150000 'de 1 \\
\hline 1 & Hemen hemen imkânsız & 1500000 'de $\leq 1$ \\
\hline
\end{tabular}

Tablo 2. Şiddetin geleneksel HTEA ölçeği

\begin{tabular}{|l|l|l|}
\hline Sıra & Etkinin şiddeti(S) & \multicolumn{1}{c|}{ Etki } \\
\hline 10 & Tehlikeli & Hata tehlikelidir ve uyarı olmadan gerçekleşir. Sistemdeki işleri erteler. \\
\hline 9 & Ciddi & Uyarı yaparak sistem işlerini etkiler. \\
\hline 8 & Aşırı & Güvenliği tehlikeye atmadan tahrip edici hatayla işletilemeyen sistem \\
\hline 7 & Büyük & Ekipman zararıyla işletilemeyen sistem \\
\hline 6 & Önemli & Küçük zararla işletilemeyen sistem \\
\hline 5 & Orta & Hata olmadan işletilemeyen sistem \\
\hline 4 & Düşük & Önemli derecede performans azalışılla işletilebilir sistem \\
\hline 3 & Az & Biraz performans azalışılla işletilebilir sistem \\
\hline 2 & Çok az & Küçük bir müdahaleyle işletilebilir sistem \\
\hline 1 & Hiç & Etkisiz \\
\hline
\end{tabular}

Tablo 3. Saptanabilirliğin geleneksel HTEA ölçeği

\begin{tabular}{|l|l|l|}
\hline Sıra & Saptanabilirlik (D) & \multicolumn{1}{|c|}{ Tasarım kontrolüyle saptanabilirliğin olabilirliği } \\
\hline 10 & Mutlak belirsiz & Tasarım kontrolü potansiyel hata sebebini belirleyemez. \\
\hline 9 & Çok uzak & $\begin{array}{l}\text { Tasarım kontrolünün potansiyel hata sebebini belirlemesi çok uzak } \\
\text { ihtimal }\end{array}$ \\
\hline 8 & Uzak & Tasarım kontrolünün potansiyel hata sebebini belirlemesi uzak ihtimal \\
\hline 7 & Çok düşük & $\begin{array}{l}\text { Tasarım kontrolünün potansiyel hata sebebini belirlemesi çok düşük } \\
\text { ihtimal }\end{array}$ \\
\hline 6 & Düşük & $\begin{array}{l}\text { Tasarım kontrolünün potansiyel hata sebebini belirlemesi düşük } \\
\text { ihtimal }\end{array}$ \\
\hline 5 & Orta & Tasarım kontrolünün potansiyel hata sebebini belirlemesi orta ihtimal \\
\hline 4 & Biraz yüksek & $\begin{array}{l}\text { Tasarım kontrolünün potansiyel hata sebebini belirlemesi biraz yüksek } \\
\text { ihtimal }\end{array}$ \\
\hline 3 & Yüksek & $\begin{array}{l}\text { Tasarım kontrolünün potansiyel hata sebebini belirlemesi yüksek } \\
\text { ihtimal }\end{array}$ \\
\hline 2 & Çok yüksek & $\begin{array}{l}\text { Tasarım kontrolünün potansiyel hata sebebini belirlemesi çok yüksek } \\
\text { ihtimal }\end{array}$ \\
\hline 1 & Neredeyse kesin & $\begin{array}{l}\text { Tasarım kontrolü potansiyel hata sebebini nerdeyse kesin olarak } \\
\text { belirleyecek. }\end{array}$ \\
\hline
\end{tabular}


Yukarıda açıklanan dezavantajların üstesinden gelmek için bulanık mantık HTEA'da yaygın olarak kullanılmaktadır (Sharma vd., 2005; Xu vd., 2002; Liu vd., 2012; Wang vd., 2009). B-PROMETHEE yönteminin uygulanması sonucu elde edilen sonuçlar gelecek bölümde incelenecektir.

\section{Bulanık Promethee Yöntemi}

PROMETHEE yöntemi, Brans tarafından 1986 yılında geliştirilmiş fayda fonksiyonları ile kıyaslanamazlık problemini aşabilen çok kriterli karar verme tekniğidir. Dilsel değişkenler ve PROMETHEE yönteminin bir kombinasyonu olan Bulanık PROMETHEE yöntemi ise ilk kez Lé Teno ve Mareschal (1998) tarafından öne sürülmüştür. Goumas ve Lygerou (2000) çalışmasında bir alçak 1sıda jeotermal alana ait enerji soğurma planları alternatiflerinin siralanması ve değerlendirilmesi için B-PROMETHEE kullanmıştır. Bilsel vd. (2006) hastane web sitelerinin performanslarını değerlendiren kalite modeli geliştirmişler ve bu performansları B-PROMETHEE yöntemi ile analiz etmişlerdir. Liu ve Guan (2009) çalışmalarında demiryolları yolcu hizmetleri kalitesini belirlemek amaciyla, yamuksal bulanık sayılar kullanarak dilsel verileri bulanık sayılara dönüştürmüş, alternatifler arasındaki bulanık ilişkileri ve bulanık akışları yine bu sayılar yardımı ile hesaplayarak, PROMETHEE II sürecini bulanıklaştırmışlardır. Ho (2006) çalışmasında ERP (Enterprise Resource Planning-Kurumsal Kaynak Planlama) sistemlerinin geliştirilme yöntemleri ve kurulum stratejilerini değerlendirmek için bulanık mantık ve ÇKKV'yi birleştirerek bulanık VIKOR (uzlaşık sıralama yöntemi) ve bulanık PROMETHEE yöntemlerini uygulamıştır. Liu ve Guan (2009) çalışmalarında demiryolları yolcu hizmetleri kalitesini belirlemek amaciyla, yamuksal bulanık sayılar kullanarak dilsel verileri bulanık sayılara dönüştürmüş, alternatifler arasındaki bulanık ilişkileri ve bulanık akışları yine bu sayılar yardımı ile hesaplayarak, PROMETHEE II sürecini bulanıklaştırmışlardır. Liao (2009)'nun otomatik yazılım geliştirmede karşılaşılan seçim problemleri konusunda, karar verme sürecindeki çatışmaları gidermek ve karar vermeyi sistematik olarak matematikselleştirmek amaciyla PROMETHEE yöntemi bulanık küme teorisi ile uygulanmıştır. Dadzie vd. (2015), çalışmalarında kamu girişimcilik sermayesi alanında B-Promethee yöntemini kullanarak en iyi işletmeyi seçmişlerdir.

PROMETHEE metodunun çok yaygın olarak başarılı bir şekilde kullanılmasının temelinde matematiksel özellikleri ve kolay kullanımı gelmektedir. Ancak, yöntemde kullanılan girdi değerleri karar vericilerin düşünce ve tecrübelerine dayandığı ve dolayısıyla dilsel terimlerle ifade edildiği zaman oluşan belirsizlik ve bulanıklıktan ötürü yanlış değerlendirmeler yaparak yanlış sonuçlara varma olasılığı çok yüksektir. $\mathrm{Bu}$ belirsizliğin yol açabileceği sorunların önüne geçmek amacıyla, bulanık sayılar ve PROMETHEE yönteminin bir kombinasyonu olan Bulanık PROMETHEE (BPROMETHEE) yöntemi geliştirilmiştir.

$\mathrm{Bu}$ çalışmada B-PROMETHEE metodu Goumas ve Lygerou (2000), Le Teno ve Mareschal (1998) ve Bilsel vd. (2006) tarafından önerilen şekilde uygulanmıştır. Dolayısıyla PROMETHEE yöntemindeki tüm işlemler ve hesaplamalar bulanık sayılarla gerçekleştirilecek olup, tercih eşik değerleri $(q$ ve $p)$ ve ağırlıklar kesin sayı olarak kalacaktır. $q$ ve $p$, bir bulanık sayının esnetilmiş biçiminden dolayı yapılacak değerlendirmelerin belirsiz olmasının engellenmesi için bulanık sayı değildir. Aynı şekilde ağırlıklar, PROMETHEE metodunda ağırlıklar toplamının 1 olması gerektiğinden dolayı işlem çözümünde bulanık sayı olarak kullanılamaz (Yılmaz ve Dağdeviren, 2010).

Uygulamada tercih fonksiyonlarının belirlenmesi aşamasında B-PROMETHEE uygulamalarında en sik kullanılan ve problemin karakteristiğine en uygun olan doğrusal tercih fonksiyonu (5. Tip) seçilmiş ve Eş. (2)'de gösterilmiştir. Bu çalışmada kullanılacak olan bulanık değerler Tablo 4'te verilmiştir.

$\mathrm{P}(\mathrm{a}, \mathrm{b})=0, \quad \mathrm{x} \leq \mathrm{q}$ 
$\mathrm{P}(\mathrm{a}, \mathrm{b})=(\mathrm{x}-\mathrm{q}) /(\mathrm{p}-\mathrm{q}), \quad \mathrm{q}<\mathrm{x}<\mathrm{p}$

$\mathrm{P}(\mathrm{a}, \mathrm{b})=1, \quad \mathrm{x}>\mathrm{p}$

B-PROMETHEE kullanıldığında Eş. (2)'de bulunan $\alpha$ ve $\beta$ eylemlerinin performansları arasındaki fark $d, \quad(n, c, d)$ bulanık sayısı olarak ifade edilecek ve Eş. (3)'teki gibi olacaktır.

$\mathrm{P}(\mathrm{a}, \mathrm{b})=0, \quad \mathrm{n}-\mathrm{c} \leq \mathrm{q}$

$\mathrm{P}(\mathrm{a}, \mathrm{b})=\frac{(\mathrm{n}, \mathrm{c}, \mathrm{d})-\mathrm{q}}{\mathrm{p}-\mathrm{q}}, \mathrm{q} \leq \mathrm{n}-\mathrm{c}$ ve $\mathrm{n}+\mathrm{d} \leq \mathrm{p}$

$\mathrm{P}(\mathrm{a}, \mathrm{b})=1, \quad \mathrm{n}+\mathrm{d} \geq \mathrm{p}$

\section{Uygulama}

Geleneksel HTEA risk faktörlerinin, önem derecelerini dikkate almadığ 1 ve $\mathrm{O}, \mathrm{S}$ ve D risk faktörlerini tam olarak değerlendirmenin kolay olmadığı kapsamlı olarak öne sürülmektedir (Liu vd., 2012; Zhou ve Thai, 2016). Çünkü geleneksel HTEA herhangi bir nicel ifade ile değerlendirmeye tabi tutulamayacağı için ancak nitel olarak değerlendirilebilir. Ayrıca, karar matrisine girdi teşkil eden değerler karar vericilerin sübjektif değerlendirmelerin dayalı olduğu için belirsizlik ve bulanıklıktan ötürü problemin çözümünde yanlış sonuçlara varılabilir. Dolayısıyla; bu uygulamada, risk faktörleriyle geleneksel HTEA'nın sözel ifadelerle değerlendirilmesine olanak sağlayan bulanık PROMETHEE yöntemi ile hata türlerinin risk öncelikleri belirlenmiştir.

Bir inşaat firmasında yeterli bilgi ve tecrübeye sahip bir inşaat mühendisi, bir iş güvenliği uzmanı ve bir akademisyenden oluşan 3 kişilik bir uzman ekip oluşturulmuştur. İnşaat firmasındaki riskleri değerlendirmek için her bir uzmana anket uygulanarak veriler elde edilmiştir. Hata türlerinin risk önceliklerinin belirlenmesinde aşağıdaki adımlar izlenecektir:

1. Uygulamada ilk olarak karar verme takımının oluşturulması ve daha sonra değerlendirmede yer alacak alternatif hata türlerinin belirlenmesi,

2. Hata türlerinin risk önceliklerinin belirlenmesinde kullanılacak olan dilsel değişken aralıklarının belirlenmesi,

3. Dilsel değişken kullanılarak risk faktörlerine ait ağırlıkların belirlenmesi ve her bir risk faktörü açısından hata türlerinin değerlendirilmesi,

4. Bulanık PROMETHEE yöntemi ile hata türlerinin risk önceliklerinin belirlenmesi.

Tablo 4. Problemin değerlendirilmesinde yararlanılan sözel ifadeler ve bulanık üçgen sayı olarak karşılıkları

\begin{tabular}{|l|l|}
\hline Sözel İfadeler & Üçgen Bulanık Sayı Karşılı̆̆ı \\
\hline Çok Yüksek (ÇY) & $(0,8 ; 1 ; 1)$ \\
\hline Yüksek (Y) & $(0,65 ; 0,8 ; 1)$ \\
\hline Orta Yüksek (OY) & $(0,5 ; 0,65 ; 0.8)$ \\
\hline Orta (O) & $(0,3 ; 0,5 ; 0,65)$ \\
\hline Orta Düşük (OD) & $(0,15 ; 0,3 ; 0,5)$ \\
\hline Düşük (D) & $(0 ; 0,15 ; 0,3)$ \\
\hline Çok Düşük (ÇD) & $(0 ; 0 ; 0,15)$ \\
\hline
\end{tabular}




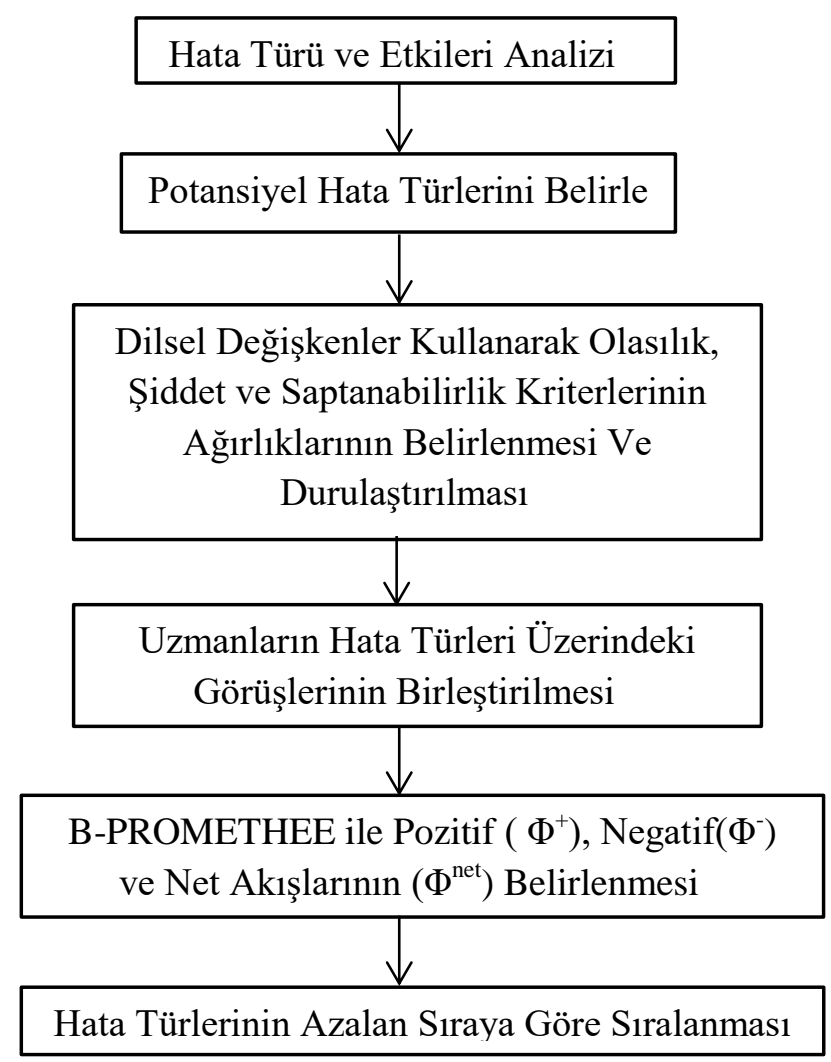

Şekil 1. Önerilen yaklaşımın akış şeması

Tablo 4'te problemin çözümünde kullanılacak dilsel değişkenler ve sayısal karşılıkları verilmiştir. Tablo $5^{\text {'te }}$ ise uygulama alanı olarak seçilen inşaattaki hata türleri gösterilmiş̧ir. Tablo 4 'te verilen dilsel değişkenlerin kullanılmasıyla olușturulan 3 takım üyesine ait risk faktörlerinin ağırlık değerlendirmesi Tablo 6'da ve hata türlerinin risk faktörü değerlendirmesi Tablo 7'de görülmektedir. Kriter ağırlıkları ve alternatif hata türlerinin toplu olarak risk faktörleri değerlendirme matrisi ise Tablo 8'de verilmiştir. Ayrıca, kriter ağılıkları PROMETHEE yönteminin uygulama prensipleri kriter ağılılıklarının toplamının 1 olmasını gerektirdiğinden bulanık değişkenlerin durulaştırılması işleminden sonra elde edilen değerler toplam ağırlık değerleri 1 olacak şekilde yeniden oranlanmıştır.

Tablo 5. İnşaat Sektörü Hata Türleri

\begin{tabular}{|l|l|}
\hline Kod & Hata Türleri \\
\hline HT1 & Yüksekten Düşme \\
\hline HT2 & Elektrikle Temas \\
\hline HT3 & Parça Düşmesi \\
\hline HT4 & Ağır Ekipman Kazaları \\
\hline HT5 & Site Trafik Yoğunluğu \\
\hline HT6 & İnşaat Yapısının Yıkımı \\
\hline HT7 & Çöküntü \\
\hline HT8 & Diğer Kazalar \\
\hline HT9 & Yangın veya Patlama \\
\hline HT10 & Yüze veya vücudun bir bölgesine tehlikeli parça sıçramas1 \\
\hline
\end{tabular}


Tablo 6. Üç Takım üyesine ait risk faktörlerinin ağırlıkları

\begin{tabular}{|c|c|c|c|c|}
\hline Takım Üyeleri & & KV1 & KV2 & KV3 \\
\hline \multirow{3}{*}{ Risk Faktörüu } & O & Y & Y & ÇY \\
\cline { 2 - 5 } & S & OY & ÇY & OY \\
\cline { 2 - 5 } & D & ÇY & O & Y \\
\hline
\end{tabular}

Tablo 7. HTEA takım üyelerine ait risk faktörü değerlendirmesi

\begin{tabular}{|c|c|c|c|c|c|c|c|c|c|c|}
\hline \multirow{2}{*}{\begin{tabular}{|c|} 
Risk Faktörü \\
Takım Üyeleri \\
\end{tabular}} & & \multicolumn{3}{|c|}{$\mathbf{O}$} & \multicolumn{3}{|c|}{$\mathbf{S}$} & \multicolumn{3}{|c|}{ D } \\
\hline & & KV1 & KV2 & KV3 & KV1 & KV2 & KV3 & KV1 & KV2 & KV3 \\
\hline \multirow{10}{*}{ Hata Türleri } & HT1 & OD & OD & $\mathrm{D}$ & $\mathrm{O}$ & $\mathrm{Y}$ & OY & $\mathrm{Y}$ & ÇY & $\mathrm{Y}$ \\
\hline & HT2 & ÇD & $\mathrm{D}$ & OY & ÇY & $Y$ & $\mathrm{Y}$ & $\mathrm{O}$ & D & $\mathrm{Y}$ \\
\hline & HT3 & ÇD & OD & $\mathrm{O}$ & $\mathrm{Y}$ & $\mathrm{OY}$ & $\mathrm{O}$ & ÇD & $\mathrm{OY}$ & ÇD \\
\hline & HT4 & $\mathrm{O}$ & $\mathrm{OY}$ & $\mathrm{D}$ & $\mathrm{O}$ & $\mathrm{O}$ & OD & ÇD & OD & ÇD \\
\hline & HT5 & $\mathrm{D}$ & $\mathrm{D}$ & $\mathrm{D}$ & $\mathrm{O}$ & $\mathrm{OY}$ & ÇD & $Y$ & ÇY & $\mathrm{Y}$ \\
\hline & HT6 & $\mathrm{D}$ & ÇD & ÇD & ÇY & ÇY & $\mathrm{Y}$ & $\mathrm{Y}$ & ÇY & $\mathrm{O}$ \\
\hline & HT7 & ÇD & $\mathrm{O}$ & $\mathrm{O}$ & $\mathrm{Y}$ & $\mathrm{O}$ & ÇY & $\mathrm{D}$ & ÇD & ÇD \\
\hline & HT8 & $\mathrm{O}$ & OD & $\mathrm{D}$ & $\mathrm{D}$ & $\mathrm{D}$ & OD & $\mathrm{O}$ & $\mathrm{O}$ & $\mathrm{Y}$ \\
\hline & HT9 & $\mathrm{O}$ & $\mathrm{Y}$ & OD & ÇY & ÇY & $\mathrm{Y}$ & ÇD & $\mathrm{O}$ & $\mathrm{D}$ \\
\hline & HT10 & $\mathrm{O}$ & $\mathrm{Y}$ & OD & $\mathrm{Y}$ & $\mathrm{OY}$ & OY & $\mathrm{D}$ & $\mathrm{D}$ & $\mathrm{D}$ \\
\hline
\end{tabular}

Tablo 8. Alternatif hata türlerinin toplu olarak risk faktörleri değerlendirme matrisi

\begin{tabular}{|c|c|c|c|c|}
\hline Risk Faktörü & & O & S & D \\
\hline Ağırlıklar & & $(0.65,0.93,1)$ & $(0.5,0.77,1)$ & $(0.3,0.77,1)$ \\
\hline \multirow{5}{*}{ Hata Türleri } & HT1 & $(0,0.25,0.5)$ & $(0.3,0.65,1)$ & $(0.65,0.87,1)$ \\
\cline { 2 - 5 } & HT2 & $(0,0.27,0.8)$ & $(0.65,0.87,1)$ & $(0,0.48,1)$ \\
\cline { 2 - 5 } & HT3 & $(0,0.27,0.65)$ & $(0.3,0.65,1)$ & $(0,0.22,0.8)$ \\
\cline { 2 - 5 } & HT4 & $(0,0.43,0.8)$ & $(0.15,0.43,0.65)$ & $(0,0.1,0.5)$ \\
\cline { 2 - 5 } & HT5 & $(0,0.15,0.3)$ & $(0,0.38,0.8)$ & $(0.65,0.87,1)$ \\
\cline { 2 - 5 } & HT6 & $(0,0.05,0.3)$ & $(0.65,0.93,1)$ & $(0.3,0.77,1)$ \\
\cline { 2 - 5 } & HT7 & $(0,0.33,0.65)$ & $(0.3,0.77,1)$ & $(0,0.05,0.3)$ \\
\cline { 2 - 5 } & HT8 & $(0,0.32,0.65)$ & $(0,0.2,0.5)$ & $(0.3,0.6,1)$ \\
\cline { 2 - 5 } & HT9 & $(0.15,0.53,1)$ & $(0.65,0.93,1)$ & $(0,0.22,0.65)$ \\
\cline { 2 - 5 } & HT10 & $(0.15,0.53,1)$ & $(0.5,0.7,1)$ & $(0,0.15,0.3)$ \\
\hline
\end{tabular}

$\mathrm{Bu}$ bölümde karar vericilerin düşünce ve tecrübelerine dayanılarak oluşturulan girdi verilerinde bulunan dilsel terimlerin yol açtı̆g belirsizlik ve bulanıklıktan doğabilecek olan yanlış değerlendirme olasılığının önüne geçmek amacıyla, Bulanık PROMETHEE (B-PROMETHEE) metodu ile hata türlerinin risk önceliklerinin belirlenmesi problemi için farklı bir çözüm yapılmıştır. Literatürde yer alan çalışmalardan yararlanılarak (Goumas ve
Lygerou, Le Teno ve Mareschal, Bilsel vd.) uygulamada kullanılacak olan doğrusal tercih fonksiyonu için farksızlık eşiği q tüm kriterler için sıfır, tercih eşiği $\mathrm{p}$ ise 0.60 alınmıştır. Değerlendirme sonucunda elde edilen pozitif $\left(\Phi^{+}\right)$ve negatif $\left(\Phi^{-}\right)$üstünlükler ile tam siralama değerleri $\left(\Phi^{\text {net }}\right)$ Tablo 10 'da, BPROMETHEE II ile elde edilen tam sıralama ise Şekil 1'de gösterilmiştir. 
Tablo 9. B-PROMETHEE metodu için elde edilen akışlar

\begin{tabular}{|c|c|c|c|}
\hline Alternatifler & $\boldsymbol{\Phi}^{+}$ & $\boldsymbol{\Phi}^{-}$ & $\boldsymbol{\Phi}^{\text {net }}$ \\
\hline HT1 & 3.422 & 4.249 & -0.827 \\
\hline HT2 & 4.585 & 3.056 & 1.529 \\
\hline HT3 & 3.00 & 5.00 & -2.00 \\
\hline HT4 & 3.262 & 4.768 & -1.506 \\
\hline HT5 & 2.721 & 5.279 & -2.558 \\
\hline HT6 & 4.067 & 3.202 & 0.865 \\
\hline HT7 & 3.877 & 4.196 & -0.319 \\
\hline HT8 & 3.654 & 5.346 & -1.692 \\
\hline HT9 & 5.475 & 1.495 & 3.98 \\
\hline HT10 & 4.621 & 2.093 & 2.528 \\
\hline
\end{tabular}

\section{$\mathrm{HT} 9 \rightarrow \mathrm{HT} 10 \rightarrow \mathrm{HT} 2 \rightarrow \mathrm{HT} 6 \rightarrow \mathrm{HT} 7 \rightarrow \mathrm{HT} 1 \rightarrow \mathrm{HT} 4 \rightarrow \mathrm{HT} 8 \rightarrow \mathrm{HT} 3 \rightarrow \mathrm{HT} 5$}

Şekil 2. Bulanık PROMETHEE ile elde edilen tam sıralama

Bulanık PROMETHEE ile elde edilen sonuçlara göre, net akış değeri yüksek olan hata türlerinin önlenebilirliği yüksek ihtimal olduğu için daha az risk oluşturmaktadırlar. Dolayısıyla, net akış değeri en düşük olan "Site Trafik kazaları (HT5)" risk faktörü en düşük hata türü ve net akış değeri en yüksek olan "Yangin veya patlama (HT9)" ise risk faktörü en yüksek hata türü olarak görülmektedir.

\section{Sonuç}

Türkiye'de iş sağlığı ve güvenliği konusuna olan ilgi her geçen gün artmaktadır. $\mathrm{Bu}$ çalışmada bir inşaattaki risk değerlendirmesi için HTEA metodundan faydalanılmıştır. HTEA'nın temel felsefesi olan riskleri sıralama yaklaşımı için bir sıralama metodu olan PROMETHEE yaklaşımı uygun bir metot olduğundan bu çalışmada incelenmiştir. PROMETHEE metodu matematiksel özellikleri ve kolay kullanımı nedeniyle yaygın olarak kullanılmaktadır. Geleneksel HTEA'da O,S ve D risk faktörleri değerlendirilirken kesin sayıların kullanıldı $\breve{g}_{1}$ 1-10 ölçeği yerine uzmanların görüşlerini daha kolay ifade edebileceği dilsel değişkenler kullanılmıştır. $\mathrm{Bu}$ çalışmada değerlendirmeyi yapan uzmanlar görüşlerini dilsel terimleri kullanarak yaptığından dolayı bulanık mantık yaklaşımından yararlanılmıştır. Böylece bulanık mantık ve PROMETHEE yaklaşımlarının birleştirilmesi sonucunda hata türlerinin suralanması için bulanık PROMETHEE yöntemi önerilmiştir.

En düşük ve en yüksek RÖS'e sahip riskler sirasıyla "Site Trafik kazaları" ve "Yangın veya patlama" olarak belirlenmiştir. Yapılan hesaplamalar sonucu "yangin veya patlama" riskinin saptanabilirlik kriter değeri oldukça

düşük olmakla birlikte olasılık ve şiddet kriter değerleri de yüksek olduğu için ilk ele alınması gereken risk olarak ve "site Trafik kazaları" riskinin saptanabilirlik kriter değeri oldukça yüksek olmakla birlikte olasılık ve şiddet kriter değerleri de düşük olduğu için en son ele alınması gereken risk olarak belirlenmiştir. PROMETHEE yönteminin sonuçlarından biri olan pozitif akışa göre "Yangın veya patlama" riski en yüksek değere sahipken "Site Trafik kazaları" ise en düşük değere sahiptir. Elde edilen sonuçlara göre negatif akış için tam tersi bir durum söz konusudur. $\mathrm{Bu}$ sonuçlar "Yangın veya patlama" riskinin mutlak önceliğini net bir biçimde ortaya koymaktadır. 
Çalışmanın iki eksikliği söz konusu olabilir. Birincisi, bu çalışmada inşaat firmasındaki riskleri değerlendirebilecek yeterli bilgi ve tecrübeye sahip uzman sayısının azlığından dolayı 3 uzmanın görüşüne başvurulmuştur. Daha fazla uzmandan görüş alınması sonuçlarda değişikliğe sebep olabilir. İkincisi, B-PROMETHEE yönteminde kullanılan $p$ ve q tercih eşik değerleri farklı alındığı zaman inşaat firmasındaki risklerin sıralaması farklı olabilir.

Gelecekteki çalışmalarda HTEA'nın değerlendirilmesi için farklı çok ölçütlü karar verme tekniklerinin hibrid yaklaşımlarından yararlanılabilir. Ayrıca bu çalışmada önerilen yaklaşım personel seçimi, tedarikçi seçimi, yazılım seçimi, tesis yer seçimi gibi farklı uygulama alanlarında kullanılabilir.

\section{Kaynaklar}

Bilsel, R. U., Büyüközkan, G., Ruan, D., “A fuzzy prefernce-ranking model for a quality evaluation of hospital web sites", International Journal of Intelligent Systems, 21: 1181-1197 (2006).

Bowles, J. B., Pelaez, C. E., 1995. Fuzzy logic prioritization of failures in a system failure mode, effects and criticality analysis, Reliability Engineering \& System Safety, 50(2), 203-213.

Brans J.P. and Vincke P. A. (1985). Preference Ranking Organizastion Method: The PROMETHEE Method for MCDM. Management Science, 31, 647-656.

Chang, D.S., Sun, K.L.P., 2009. Applying DEA to enhance assessment capability of FMEA. International Journal of Quality \& Reliability Management, 26, 629-643.

Chang, K.H., Chang, Y.C, ve Tsai, I.T., 2013a. Enhancing FMEA assessment by integrating grey relational analysis and the decision making trial and evaluation laboratory approach, Eng. Fail. Anal., 31, 211-224.

Chang, K. H., Liaw, C.-S., Chang, T.-Y., Chang, Y.-C., 2013b. FMEA-based DEMATEL apportionment approach. Chung Cheng Ling Hsueh Pao/Journal of Chung Cheng Institute of Technology, 42(1), 41-58.

Dadzie E., Oplatková Z., Nabareseh S., "Selecting Start-Up Businesses in a Public Venture Capital Financing using Fuzzy PROMETHEE", Procedia Computer Science, Volume 60, Pages 63-72 (2015).

Ford Motor Company, 1988. Potential failure mode and effects analysis (FMEA) reference manual.

Goumas, M., Lygerou, V., 2000. An extension of the PROMETHEE method for decision making in fuzzy environment: Ranking of alternative energy exploitation projects, European Journal of Operational Research, 123, 606-613.

Ho, C., “Applying fuzzy multicriteria decision-making for evaluating ERP system development methods and implementation strategies", Yüksek Lisans Tezi, I-Shou Üniversitesi Bilgi Yönetimi Bölümü, 1-3 (2006).

Kutlu, A. C., \& Ekmekcioğlu, M., 2012. Fuzzy failure modes and effects analysis by using fuzzy TOPSIS-based fuzzy AHP. Expert Systems with Applications, 39(1), 61-67.

Le Téno, J., F., ve Mareschal, B., “An interval version of PROMETHEE for the comparison of building products' design with ill-defined data on environmental quality", Eur Journal of Operational Research, 109, 522-529, 1998.

Liao, T. H., "Automatic program design framework in PC-BASE equipment research", Yüksek Lisans Tezi, I-Shou 
Üniversitesi Bilgi Yönetimi Bölümü, 13, (2009).

Liu H.C., Liu L., Liu N., Mao L. X., 2012. Risk evaluation in failure mode and effects analysis with extended VIKOR method under fuzzy environment, Expert Systems with Applications, 39, 12926-12934.

Liu H. C., Liu L., Li P., Failure mode and effects analysis using intuitionistic fuzzy hybrid weighted Euclidean distance operator, International Journal of Systems Science 45(10) (2014) 20122030.

Liu, H. C., You, J. X., Shan, M. M., \& Shao, L.N., 2015. Failure mode and effects analysis using intuitionistic fuzzy hybrid TOPSIS approach, Soft Computing, 19(4), 1085-1098.

Liu P., Guan Z., "Evaluation research on the quality of the railway passenger service based on the linguistic variables and the improved PROMETHEE-II method", Journal of Computers, 4 (3): 265-270 (2009).

Özfirat, P.M., 2014. Bulanık önceliklendirme metodu ve hata türü ve etkileri analizini birleştiren yeni bir risk analizi yöntemi, Journal of the Faculty of Engineering and Architecture of Gazi University, 29(4), 755-768.

Sachdeva, A., Kumar, D., Kumar, P.A., 2008. Methodology to Determine Maintenance Criticality using AHP. International Journal of Productivity and Quality Management, 3(4), 396412.

Sankar, N. R., Prabhu, B.S., 2001. Modified approach for prioritization of failures in a system failure mode and effects analysis, International Journal of Quality \& Reliability Management, 18(3), 324-336.
Seyed-Hosseini, S.M., Safaei, N., Asgharpour, M.J. (2006). Reprioritization of failures in a system failure mode and effects analysis by decision making trial and evaluation laboratory technique. Reliability Engineering and System Safety, 91(8), 872-881.

Sharma, R. K., Kumar, D., \& Kumar, P., 2005. Systematic failure mode effect analysis (FMEA) using fuzzy linguistic modelling, International Journal of Quality \& Reliability Management, 22(9), 986-1004.

Song, W., Ming, X., Wu, Z., Zhu, B., 2013. Failure modes and effects analysis using integrated weight-based fuzzy TOPSIS, International Journal of Computer Integrated Manufacturing, 26(12), 1172-1186.

Song, W., Ming, X., Wu, Z., \& Zhu, B., 2014. A rough TOPSIS approach for failure mode and effects analysis in uncertain environments. Quality and Reliability Engineering International, 30(4), 473486.

Tan, Z. D., \& Du, Z.F., 2013. Failure mode and effects analysis of equipment based on grey theory. Applied Mechanics and Materials, 313, 763-766.

Wang, Y. M., Chin, K. S., Poon, G. K. K., \& Yang, J. B., 2009. Risk evaluation in failure mode and effects analysis using fuzzy weighted geometric mean. Expert Systems with Applications, 36(2), 11951207.

Vahdani, B., Salimi, M., \& Charkhchian, M., 2015. A new FMEA method by integrating fuzzy belief structure and TOPSIS to improve risk evaluation process. The International Journal of Advanced Manufacturing Technology, 77(1-4), 357-368. 
Xu, K., Tang, L.C., Xie, M., Ho, S.L., \& Zhu, M.L., 2002. Fuzzy assessment of FMEA for engine systems, Reliability Engineering \& System Safety, 75(1), 17-29.

Y1lmaz, B., Dağdeviren, M., 2010. Ekipman Seçimi Probleminde PROMETHEE ve Bulanık PROMETHEE Yöntemlerinin Karşılaştırmalı Analizi. Gazi Üniversitesi Mühendislik ve Mimarlık Fakültesi Dergisi, 25(4), 811-826.
Zhou, Q., Thai, V.V., Fuzzy and grey theories in failure mode and effect analysis for tanker equipment failure prediction, Safety Science, (2016), 83, 74-79. 